\title{
THE ROLE OF UNIVERSITIES IN SUSTAINABLE RURAL DEVELOPMENT: TOWARDS A KNOWLEDGE INTERMEDIATION MODEL OF UNIVERSITY COMMUNITY OUTREACH PROGRAMS
}

\author{
Firimooni Rweere Banugire* \\ Bishop Stuart University, Mbarara, Uganda \\ Email:*Secomi2001@yahoo.com
}

\begin{abstract}
This paper argues for recognition of the important role universities can play to promote timely, efficient and effective policy design and implementation to address the development challenges facing less developed countries like Uganda. It calls for the establishment of communityUniversity Public Partnerships (CUPPs) for knowledge management for development through collective learning for development. CUPPs can be operationalized through University-CommunityOutreach Programs (UCOPs), facilitated by governments and their development partners. The major reason is to enhance the capacity and effectiveness of service delivery partnerships. Figs 1 and 2 articulate conceptual frameworks for understanding the development role of universities as knowledge intermediaries for accelerated, sustainable rural transformation.

The model emphasizes the benefits of knowledge management for sustainable development and crisis/ disaster management. CUPPs would reduce the incidence and consequences of institutional and policy failures and generate endogenous knowledge for inclusive economic growth and sustainable human development. Outcomes would include; citizen's empowerment, improved governance systems and policy effectiveness can Universities show the way forward by putting seed capital in UCOPs and lobbying for external supports
\end{abstract}

Keywords. Knowledge intermediation, sustainable rural development, community-University-public partnerships, University-community outreach programs

\section{Introduction}

This paper argues for recognition of the important role universities can play to facilitate sustainable rural development (SRD) in partnership with the public sector and the development partners. This idea was bornout of my experience with policy, program and research consultancy for public, private and civil society organizations. Whereas the private sectors actors' roles have been recognized and institutionalized through private- public partnerships (PPPs), those of civil society have been under-rated and are often subsumed under PPPs. This is because of the top-down and market liberalization approaches that are complementary in dominating the development debates. The paper therefore calls for a knowledge management partnership (KMP) between the state and its development partners on the other hand and the citizens through their organizations (both private and civil society) on the other hand to accelerate SRD for learning for development of knowledge-based economy and society. This knowledge management strategy for SRD is justified on several strategic and pragmatic grounds. 
The crisis perspective. Uganda, like most African countries is faced with economic, social, moral, ecological and governance threats or crises that require early diagnosis and prevention, as wellas correct perceptions for effective implementation. Communities must be empowered for self- diagnosis and self- help initiatives, or social entrepreneurship.

The performance perspective. The major constraints to SRD include, among others, institutional and policy failures, right from the grassroots level of civil society to the private sector partnerships, and to public sector management. A culture of performance management is critical to effective policy/ program implementation and good corporate governance.

The knowledge-for- development perspective. A major weakness of policies and programs is inadequate contextualization of good ideas borrowed from elsewhere, which demand dialogue among policy makers and policy beneficiaries with the intermediation of specialists in knowledge generation and dissemination, a role universities are designed to play, provided they are properly facilitated.

The strategic perspective. In 1990, the South Center authored a report on the challenges facing developing countries and how to address them through strategies of self-reliance, which was validated by a team of international experts (The South Centre, 1993); yet very little progress has been achieved and probably we are moving in the opposite direction.

The appropriate knowledge perspective. A number of scholars and informed observers, both Africans and non-Africans have concluded that many of the policy, institutional and governance failures are, to a large extent, due to lack of endogenous knowledge systems that foster learning-by-doing and critical thinking for knowledge transfer and dissemination (Green,2008, Mathai, 2009; Nabudere, 2010;).

The above perspectives and others demonstrate the important role Universities can play to generate and disseminate the right knowledge for development. More importantly, they underscore the fact that the time is now for Universities to be assigned an active role in the "development market place" in the form of knowledge management for development with a view to activating society and economy- wide processes of learning for development and learning- for - peace, progress and prosperity for all.In this process, Africa must "bet on its strength", the human resources and its organic links with natural resource base from time immemorial. This is the knowledge frontier where we must focus our intellectual energies to feed ourselves, to show the way to green economies and green societies and to excel in appropriate strategies of SRD. It demands localization of economic growth and of the MDGs/ SDGs to achieve prosperity for all. All regions of the country are served by rural- based universities with access to practically all communities and natural resource sites. Universities must, therefore, be facilitated to open up knowledge sites everywhere for diagnosing development problems before they reach disaster proportions. They must then link with the service delivery partnership of the public, private and community sectors to generate the right policy frameworks, institutional reforms, and cultural change strategies to put our economies on paths of sustainable rural development as inclusive growth, human development, and peaceful and prosperous communities. This is the knowledge management challenge that has been neglected since independence and that requires urgent attention.

This study was based on key informant interviews with facilitators of field work practices in five Universities, in Uganda; workshop methodology at Uganda Christian University (UCU), Bishop Barham University College (BBUC); feedback from conference proceedings, and peer- review feedbacks from colleagues

The UCU/BBUC workshop discussed the idea of knowledge intermediation as distinct from the idea of community outreach programs and the connections between them using the practices of the five universities. The results were integrated in a conference paper (Banugire 2010 (a)). This was later discussed with colleagues at two Universities including Bishop Stuart University, my current employer and the feedbacks were integrated. The main result was the concept of the community- university- public partnership for knowledge management. 
In summary, the overall approach has been critical thinking on the developmental role of universities and creative thinking to develop the model of knowledge- intermediation through university community outreach programs (KIM- UCOPs).

\section{Towards a Knowledge Intermediation model of UCOP}

\section{Rationale for universities to play a developmental role}

The first initiative is to critically review the role of African universities in society in the $21^{\text {st }}$ century. Does the university have a developmental role besides its traditional roles of knowledge generation and dissemination? The basic challenges that the knowledge management model is designed to address include, among others, the following:

- The emerging knowledge-driven economy at the global level which demands more knowledge- inclusive development management programs and practices.

- The observations by a diverse spectrum of scholars/ intellectuals that the euro-centric knowledge systems tend to devalue African creativity, agency and value systems; hence the need for domesticated knowledge systems in African contexts. (Nyamujor,2004; Nabudere, 2010)

- The increasing emphasis on institutional and organizational development as key factors in sustainable and inclusive economic growth of the less developed economies (LDCs), especially so for the least developed economies like Uganda.

- The recognition that sustainable rural development is a complex, multi-dimensional process that requires balancing the roles of the state, markets and collective community action to generate evolutionary processes of structural, social, cultural, and technological transformation (World Bank,2010; Banugire 2017).

- The limited government capabilities for effective, transparent, and socially accountable monitoring and evaluation systems for service delivery and good governance.

Given the above global challenges in a rapidly globalizing world, African countries must harness their higher institutions of learning, to play developmental roles in the form of promoting society- wide collective learning for social and economic transformation of the rural society and economies towards sustainable human development. The main reasons for the developmental roles are heighted by the following:

- Higher institutions of learning(HIL), especially universities, have an important role to play in development management; this is the knowledge management role which is the basis of effective, pro-poor governance and citizens' participation in decision making at all levels of society action.

- There is, therefore, need for a dual partnership system, whereby the community-privatepublic partnership (CUPPPs) for service delivery works hand in hand with the knowledge management partnership for research and development as well as monitoring and evaluation of the service delivery systems and the overall governance and development management systems.

- The CUPPPs are more effective and socially responsive when it follows the bottom- up approach emphasizing community organizing for good governance.

- The existing CUPPPs have been focusing on private-public partnerships, without deepening decentralization to the community level and largely ignoring the critical role of the community organizations in SRD. 


\section{The basic Assumptions of the KIM-UCOP}

Putting the above considerations together as key challenges facing LDCs, leads to the conclusion that, the challenge of knowledge management for sustainable development cannot be met by the present emphasis on public and private partnership for service delivery alone.

First, there is a need to recognize the critical role for civil society as the third pillar of partnership building. However, the proper role of CSOs must be determined through a multi-stake holder dialogue with civil society in the general and community-representatives of the citizens in particular (Green 2008).Second, active participation of citizens, is required not only for sustainable poverty reduction but also for inclusive economic growth,(Growth Commission 2004), and for effective socially responsible conservation efforts. Third evidence abounds to show that powerful economic and political interests are the drivers of environmental degradation and other policy and institutional failures. Hence the importance of independent agencies equipped with relevant and pro-people knowledge systems, as the right agencies for monitoring and evaluating these issues. Universities are by far the best candidates for such a critical roles and UCOPs are the appropriate mechanism.

Therefore, the KIM-UCOP model rests on the following major assumptions about the division of labour between states, markets and communities in the business of development management for sustainable development. The principles of economic pluralism (Banugire, 2017) is the key to getting this division of labour right to achieve RSD.

The KIM-UCOP Social Responsibility Framework

Proposition 1: Effective service delivery and development management requires a dual framework, one for service delivery and another for knowledge management.

Proposition 2: The service delivery partnership seeks to balance the roles of civil society (CSOs), the markets (PSOs) and state agencies through a bottom-up approach focusing on community organizing for sustainable rural development.

Proposition 3: The knowledge partnership is structured through university community out-reach programs as the core mechanism for knowledge exchange (sharing) among the (CSOs), PSOs and Government agencies (MDAs) (Ministries, Departments and Autonornous Agencies).

Proposition 4: The key role of government is to provide an appropriate fund for research and development (R\&D) for technological and social innovations as well as Monitoring and Evaluation (M\&E) activities.

Proposition 5: The key role of universities is localization or domestication of knowledge systems developed in other contexts as well as generating context specific knowledge that incorporates indigenous knowledge of grassroots actors and endogenous knowledge of all Stakeholders, and to localize policy frameworks such as SDGs/ MDGs that are critical for accelerating human development, inclusive growth and environmental protection.

Proposition 6: The private sector role is to provide R\&D financing for technological and business development services in partnership with government, donors and international NGOs.

Proposition 7: The civil society organization core role is community organizing for self-reliance and active participation in knowledge management and service delivery systems. 


\section{The knowledge intermediation model: A conceptual framework}

The above elements of the knowledge intermediation model of the university community- outreach programs in African universities are integrated in the conceptual framework below (fig.1) They include; the concept of knowledge intermediation three types of learning partners, clearly defined role for each partner (communities or business associations, universities, government agencies),clearly defined learning outputs by stakeholders, quality assurance mechanisms or criteria for performance management of the partners in the development process.

Knowledge Intermediation is the agency of universities in connecting policy makers and service delivery agencies on one hand with the communities and market actors as the beneficiaries of policy making and social and economic services, on the other hand. It is a multi- stakeholder partnership among the three types of participants in the development process: communities and producers and consumers of goods and services, civil society organizations of citizens, and government agencies and their development partners. Those who demand development are linked with those who promote development for the social welfare of all members of a given society (village, locality, nation, or global community of mankind).

The three learning partners in the process of knowledge generation are self-interested collaborators in the development process. Therefore, the collaboration role of the university through their university- community outreach programs (UCOPs) is essentially a developmental role. They are promoting development just like their partners, the civil society organizations (CBOs, FBOs, NGOs) or business enterprises, or government agencies and state owned e enterprise or development partners (Maliterateral Agencies, Bilateral agencies, international NGOs etc.). Universities are knowledge management agencies, responsible for Knowledge-generation and Knowledge dissemination for social actions of the other partners in the development process.

The KIM-UCOP model assumes that UCOPs should be organized as development agencies with developmental missions and strategies for sustainable rural or urban development. Their core role is research and development $(R \& D)$, which must be funded by the governments and their development partners. UCOPs must be facilitated as mobilisers of citizens for collective learning for development (CLD). Hence the key role of participatory action research (PAR) as a driver of the development process. PAR as a driver of social change may be focused on the following learning frontiers (1) CL for sustainable livelihoods, (2) CL for value chain management and governance, (3) CL for economic policy management and governance, (4) CL for public policy management for effective service delivery systems

The primary mission and focus of UCOPs would be performance management of development initiatives of civil society, social business enterprises and business enterprises. Hence the importance of the concept of developmental governance for sustainable development (Laurisden 2014). Communities and domestic markets, must be mobilized, organized and facilitated for performance management of their projects for self-help initiatives and partnerships for community development and inclusive and green growth and development (Growth commission, 2008) 


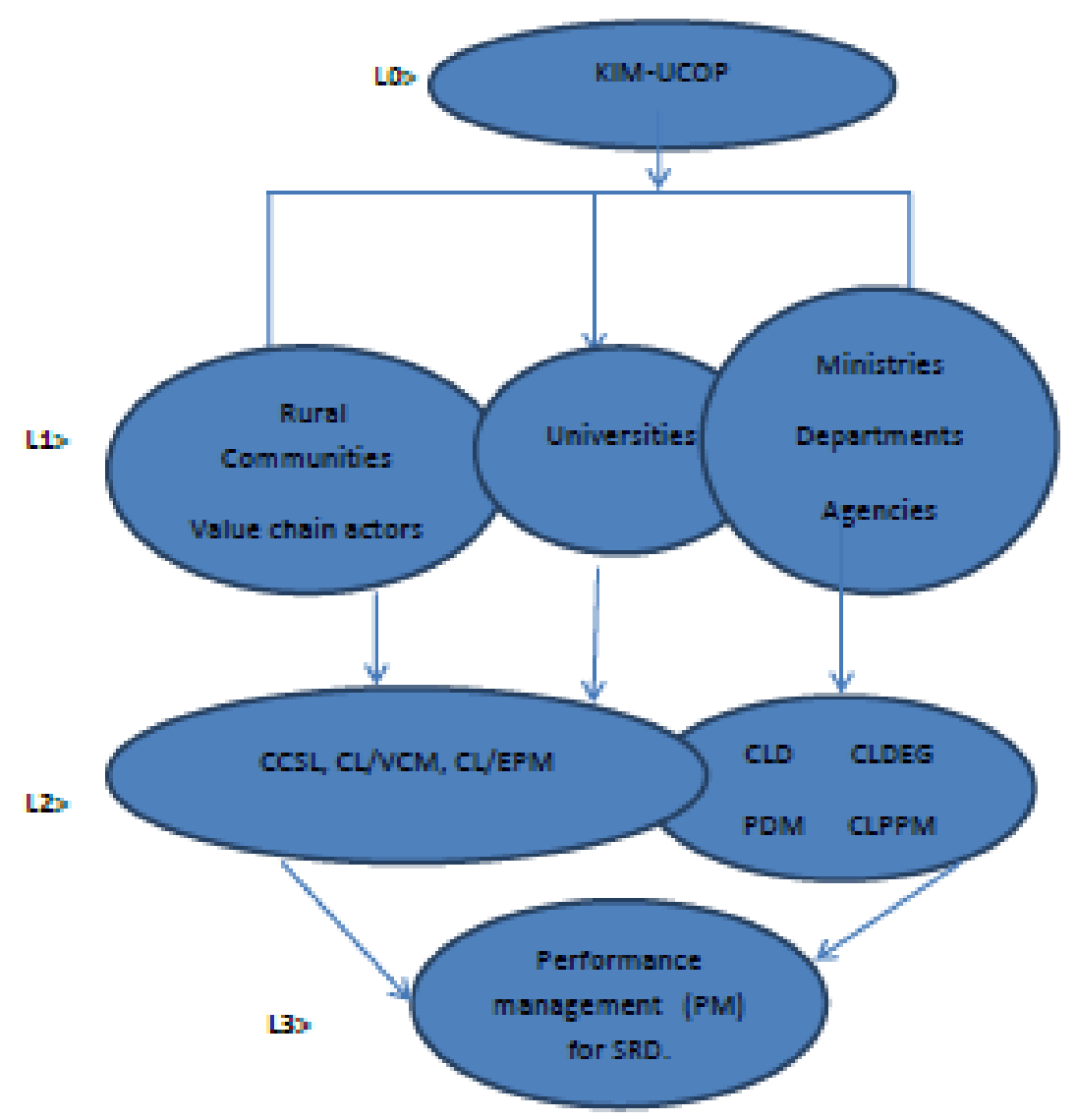

Figure 1: Knowledge intermediation model: A conceptual framework

Notes: KIM-UCOP $=$ Know ledge intermediation model of the university- community -outreach programs. $\mathrm{CLD}=$ Collective learning. $\mathrm{CLSL}=$ Collective learning for sustainable livelihoods. $\mathrm{CLVCM}=$ Collective learning for value chain management. CLPPM= Collective learning for public policy management.

L0 > Concert of KI: an analogy with financial intermediation. L1 > partnership for knowledge management (KMP). L3 > Concept of CLD: learning for what and how. L4 > Results of the KM

\section{Implications for Sustainable Rural Development}

\section{Effective Service Delivery}

The overall implication of assigning UCOPs the role of facilitating development through research and development activities as well as Monitoring and Evaluation of development initiatives is to improve performance of program design and implementation, and above all, to facilitate the growth of self-help initiatives country-wide. Key outcomes would include; deepening decentralization (now stagnating); effective community organizing for sustainable development (now lacking), up-graded role for cooperatives, and effective and fruitful partnership building for effective service delivery. Currently result oriented management (ROM)has failed to take root, and UCOPs would strategize how to ensure that partnerships and ROM flourish as tools of development. The community university public partnership for knowledge management may be 
perceived as an instrument for enhancing the effectiveness of the public-private-community partnership for effective service delivery.

\section{Towards Sustainable Rural Development}

The main advantage of establishing a knowledge based partnership for enhanced service delivery is to improve the effectiveness of government in addressing grassroots problems especially of vulnerable groups and subsistence farmers, as well as environmental degradation. However, there is a secondary benefit in form of enhanced civil society initiatives and self-reliance of rural communities (World Bank, 2010). The net effect is to accelerate rural transformation for inclusive economic growth, human development and conservation. Therefore, all partners in service delivery should welcome this social innovation, not only for effective and efficient implementation but also for improving the quality of education and employ ability of graduates of higher institutions of learning.

UCOPs would play a key role in generating and disseminating knowledge for pro-poor development programs while imparting practical skills to the learners and improving the quality of education. University graduates could be sensitized and empowered to act as job creators (social, business and technological innovators). Currently there are major performance gaps in this respect.

UCOPs would also add value to the global partnership for development (MDGs/SDGs) by strengthening the bottom-up approach to development. This would enhance the localization of SDGs thereby accelerating the processes of poverty eradication and inclusive and green growth as well as improving the effectiveness of foreign aid. All these issues are critical challenges for social and structural transformation that have not been adequately addressed in policy making (Banugire, 2017)

Therefore, the knowledge intermediation model is a tool for integrating sound knowledge management within service delivery systems for human development on one hand and sustainable, inclusive and green growth on the other hand. While developed economies can promote learning societies using business firms (Stieglitz and Green-wald 2014), developing countries of Africa can best do so through collective learning of communities' value chain actors and local government stake holders facilitated by their higher institutions of learning through developmental community outreach programs. This conclusion is consistent with "Voices of the poor from many lands" (Narayan and Patti, 2007)

\section{The knowledge management partnership as a driver of SRD}

The linkages between the two partnerships for SRD are summarized in fig.2.below.The Universities mobilize communities for functional learning for sustainable livelihoods and value chain management on one hand and for result-oriented management of public policies and localization of SDGs on the other hand. The role of CUPPs is to lay foundations for knowledge economies and societies in Africa, thereby accelerating SRD. 


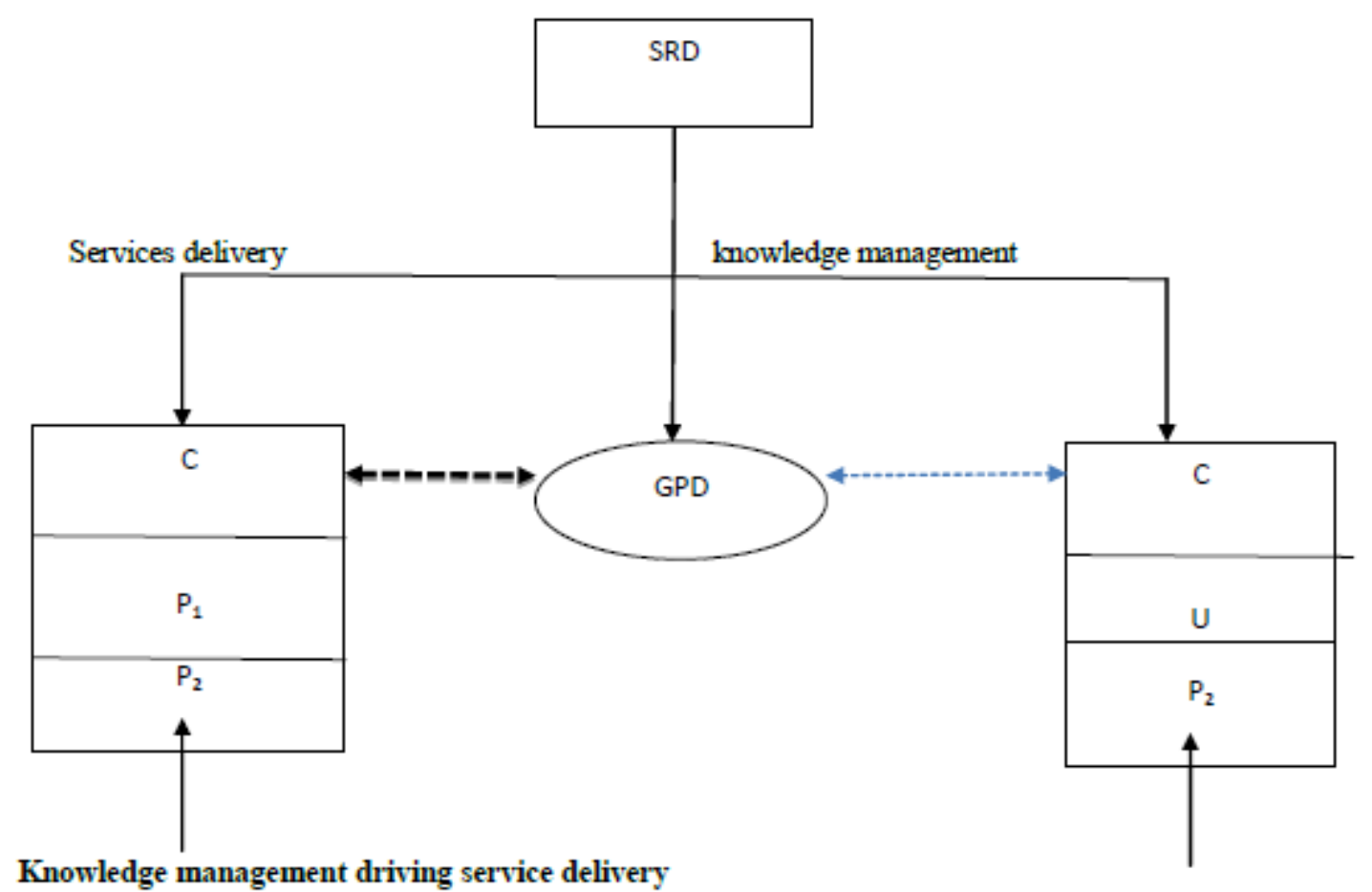

Figure2: A dual partnership frame work for knowledge driven sustainable rural development

Notes: $\quad \mathrm{C}=$ Communities $(\mathrm{CSO})$;

$\mathrm{P}_{1}=$ Private Sector Organizations (PSOs)

P2 = Public sector

UCOP = University Community Outreach Programs

GPD = Global Partnership for Development (MDG8)

$\mathrm{SRD}=$ Sustainable Rural Development.

$\mathrm{CP}_{1} \mathrm{P}_{2}=$ Service Delivery Partnerships.

CUP2 $=$ Knowledge management Partnership

\section{Implications for Environmental Management}

\section{The rationale: Why involve universities}

The global economy is now characterized as knowledge economy largely because of the diversity and rapidity of new technologies (both physical and social innovations) which have considerable impact on the social and economic lives of communities and the wider societies (Nations, Regions and all humanity). Secondly, there are global challenges that face all societies and which require responses at global level to be effectively localized at national, local and community levels. This implies wide range of stakeholders who have to be consulted, sensitized and mobilized into consensus- building for conservation at all levels, right from grass-root 
communities to the global level. Hence, the importance of evidence-based solutions, strategic decision-making and efficient resource allocation priorities. This is the challenge of knowledge management for advancing the agenda's for sustainable development, which has not been adequately met by many least Developed Countries (LDCs), especially more so by Uganda, because of the following factors

- The top-down approach to policy-making that focuses on budgeting rather that problem oriented strategic planning.

- The diversity of stake holders in natural resource management and the multipurpose nature of natural resources use, coupled with very limited capacity at local government levels, leads to failure to operationalize the legal, institutional and policy frame works recommended in various sub sector programs for forests, wetlands, fisheries, water/sanitation, ecosystems management for tourists and sustainable agriculture.

- The privatization syndrome, leading to power elites to grab environmentally sensitive resources for profiteering, regardless of the existing policies and regulations leading to a culture of impunity with respect to environmental abuse and degradation.

- The rampant culture of corruption and power-driven resources use that characterize financial resource mobilization and management, leading to a mismatch between identified challenges and action priorities that have combined to consolidate systems of economic governance and environmental governance that are power driven; not policy driven, hence wide spread policy and institutional failures

\section{How good knowledge management can help}

The most appropriate starting point to address these challenges, which are complex and interconnected, is knowledge generation.

First to expose the great gaps between policy intentions and targets and the actual realities and trends in environmental degradation as well as the institutional inadequacies and failures. For example, the failure to establish and operationalize the local environmental communities (LECs). Risk identification and mapping is key to sensitizing the public and policy makers about these gaps

Secondly, to analyze options for wise use of resources, for sound policy management and for institutional development. Design of strategic innervetions framework for the benefit of private, public and civil society actors is another missing link in wise use of natural resources. Thirdly, UCOPs can play the role of research and developments $(R \& G)$, developing solutions for specific environmental problems, in specific locations. For example UCU/BBUC Kabale campus has proposed a partnership with Kanungu districts to protect a wetland and an adjacent forest reserve through a community-driven collaborative resource management. This solution prioritizes micro and small ecosystems within agricultural areas, thereby integrating sustainable agriculture, value addition enterprises (SMEs) and environmental health. The key strategies include; among others, community organizing, business and social entrepreneurship training, business linkages, rural financial services, and linkages to environmental health services.

Lastly, UCOPs may be used to monitor and evaluate the design and implementation of various government policies with impact on sustainable development and propose policy, institutional and management reforms. The environmental surveillances and M\&E role are knowledge intermediation tasks in the interest of communitydriven sustainable rural development. 


\section{Concluding Remarks}

UGANDA, like many African countries, is facing challenges of development which the institutional and policy making capacities are not able to handle adequately. The capacity gaps are either increasing or at best remaining the same. One of the missing links is the knowledge management capacity for sustainable rural development. The most appropriate strategy, for addressing this challenge is for governments and their development partners to fund UCOPs to improve government policy management effectiveness, and energize self-help initiatives while improving the quality of education.

Accordingly, this recommendation calls for commitment to build a viable and vibrant knowledge management partnership as a tool for knowledge driven development. It means establishing a budget framework for R\&G services for learning for development to enhance capacities for effective crisis/disaster management and service delivery. This is one of the missing links in the search for good economic governance, and good environmental governance.

For Africa to survive the varied shocks of globalization and exploitation by other force, this is a way forward to knowledge based self-reliance. It is also the only way to African renaissance, whereby Africa will take charge of its destiny in partnership with forces of social justice and humanism worldwide.

Can universities convince the governments to address these challenges? This is a question that needs consensus building at national level. But the universities can start sowing the seeds of progress by establishing the UCOPs as a vehicle for change and then lobbing for partnership building.

\section{References}

Banugire F. Rweere, 2010, Towards effective climate adaptation initiatives through university outreach programs. Presentation at international conference on Climate Adaptation for Sustainable development by pilot international, at Munyonyo, Kampala, November.2010

Banugire, F.Rweere, 2010,Towards a knowledge intermediation model of University Community outreachPrograms. Presentation at UCU/BBUC Research sensitization seminar, April, 2010.

Banugire F Rweere, 2017, From Washington consensus model to Addis Ababa consensus model: lessons from Beijing consensus model

CORG, 2011, Workshop Proceedings on Research Sensitization Seminar, UCU/BBUC, Kabale Campus, July. CORG is community organizing research group for several universities.

Green, Duncan, 2008,From poverty to power: How active citizens and effective states can change the world, London: Oxfam

ILO, 2004, A fair globalization: Creating opportunities for all. ILO, Geneva

Mathai Wangari, 2009, The challenge for Africa: A new Vision. London, Random House.

Nabudere, D. 2001, Towards Establishment of a pan- African University. A Strategic Concept Paper.

Narayan Dand P. Patti, Petesch.A, 2007, Voices of the poor from many lands. World Bank Washington DC/ Oxford University Press.

The Growth Commission, 2006, Towards inclusive Economic Growth. World Bank; Washington, D.C

The South Centre, 1993, Facing the challenge to the South: The South Centre, Geneva

World Bank, 2010, Local and Community Driven Development. Washington, D, C 